$1988,37,1$

УдК $553.551 .1: 553.08: 53 / 54(474.2)$

Аада ТЭЭдУМЯЭ

\title{
ОСОБЕННОСТИ ВЗАИМОСВЯЗИ ФИЗИКО-МЕХАНИЧЕСКИХ СВОЙСТВ ИЗВЕСТНЯКОВ МЕСТОРОЖДЕНИЯ ВАЗАЛЕММА
}

Месторождение Вазалемма (Падизе Паэмурруд) находится в 40 км юго-западнее Таллина. Литературные данные о разработке месторождения относятся к XIX столетию (Eichwald, 1854). В карьере добывали известняк для изготовления строительного камня, плитчатых ступеней, скульптурных и декоративных деталей, а также для обжига на известь и в целлюлозно-бумажной промышленности. Камень, предназначенный для изготовления скульптур и использования в целлюлозной промышленности, вывозили в Петербург, Швецию, Финляндию. Сохранившиеся до настоящего времени древние постройки (монастырь Падизе и др.) свидетельствуют о разработке месторождения уже в XIV веке. В настоящее время известняки из Вазалемма используются для производства щебня, строительной извести и технологического камня, в целлюлозно-бумажной промышленности.

Месторождение приурочено к известнякам вазалеммаской $\left(\mathrm{O}_{2} \mathrm{vs}\right)$ и кахулаской $\left(\mathrm{O}_{2} \mathrm{kh}\right)$ свит среднего ордовика. В полезную толщу по подсчетам запасов 1980 г.* включены следующие основные разновидности известняков (сверху вниз):

- от мелко- до грубокристаллического, в основном от крупно-до среднекристаллического, цистоидный известняк $\left(\mathrm{O}_{2} \mathrm{Vs}\right)$, известный в практике под названием «вазалеммаский мрамор»;

- скрытокристаллический биогермный (мшанково-водорослевый) известняк, местами глинистый, содержит детрит $\left(\mathrm{O}_{2} \mathrm{vs}\right)$;

- микрокристаллический известняк с мелким детритом, полукомковатый $\left(\mathrm{O}_{2} \mathrm{kh}^{\mathrm{ps}}\right)$; $\left(\mathrm{O}_{2} \mathrm{kh}^{\mathrm{k}}\right)$.

- тонкокристаллический глинистый известняк с мелким детритом

До настоящего времени тонкокристаллические известняки куртнаской пачки $\left(\mathrm{O}_{2} \mathrm{kh}^{\mathrm{k}}\right)$ в подсчет запасов не включались. Таким образом, в объеме полезного слоя разведки 1980 г. имеется наиболее полный перечень известняков от крупно- до скрытокристаллических, физикомеханические свойства которых определены в одной лаборатории и по одной методике. Исходя из этого, первым объектом для исследования взаимосвязи физико-механических свойств известняков, развитых на территории Эстонии, было выбрано месторождение Вазалемма.

Все свойства пород бесспорно взаимосвязаны. Изменение одного из них неизбежно влечет за собой изменение какого-нибудь другого. Однако установление связей затруднено большим количеством одновременно действующих факторов, так как горные породы представляют собой многокомпонентные системы. Установление корреляционных зависимостей ограничивается обычно охватом только некоторых свойств, за которыми конкретная зависимость уже не наблюдается.

* Юргенсон В., Баранкина Н., Мыттус В., Тасса В. Отчет о результатах доразведки н пересчета запасов на месторождении известняков Вазалемма (участок Падизе Паэ-
мурруд 2). ВГФ, ЭГФ, 1980. 

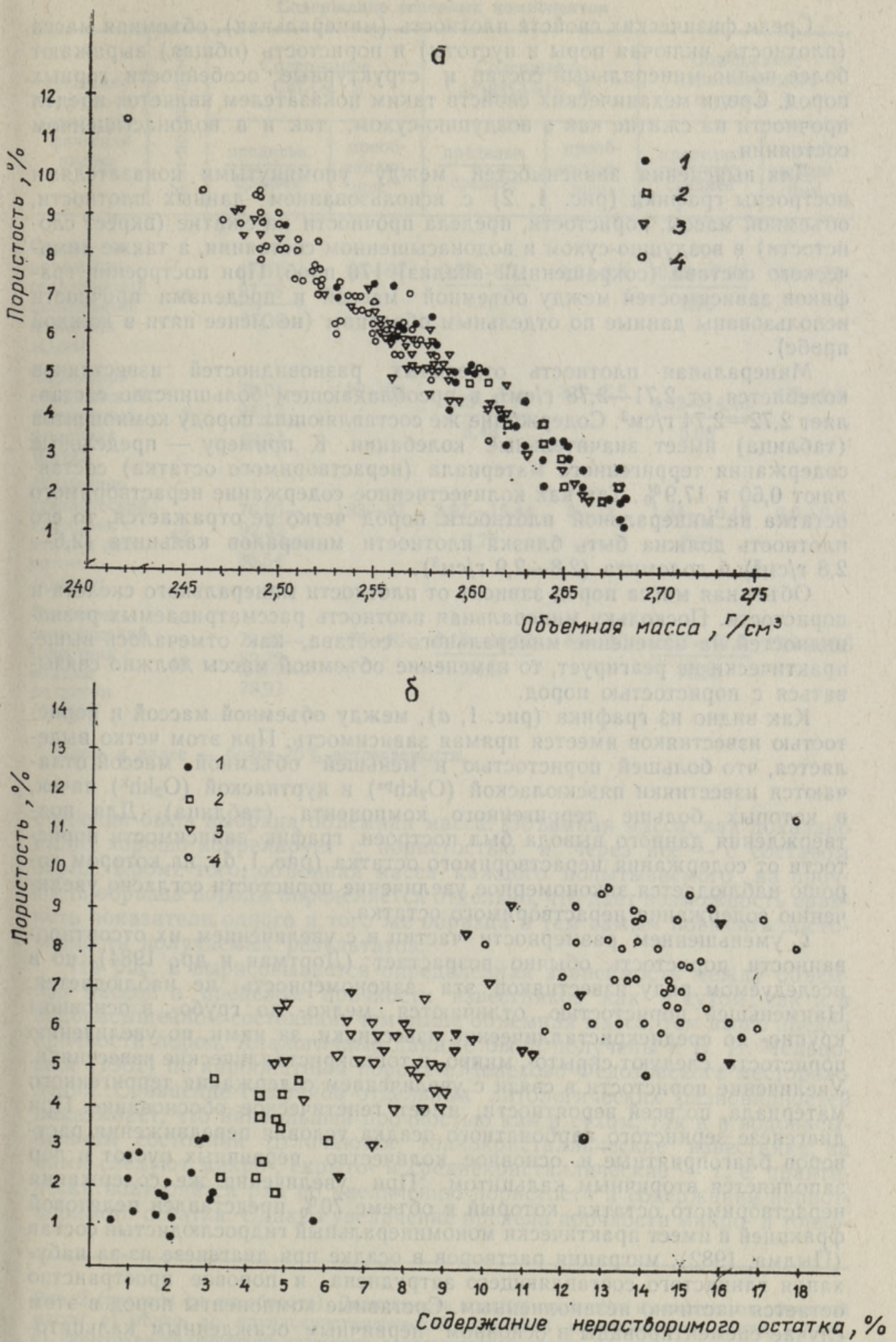

Рис. 1. Зависимость объемной массы от пористости известняков $(a)$ и пористости известняков от содержания нерастворимого остатка (б). 1 - мелко- до крупнокристаллнческий известняк, 2 - скрытокрнсталлический известняк, 3 - микрокрнсталлическнй известняк, 4 - тонкокристаллическнй известняк. 
Среди физических свойств плотность (минеральная), объемная масса (плотность, включая поры и пустоты) и пористость (общая) выражают более полно минеральный состав и структурные особенности горных пород. Среди механических свойств таким показателем является предел прочности на сжатие как в воздушно-сухом, так и в водонасыщенном состоянии.

Для выяснения зависимостей между упомянутыми показателями построены графики (рис. 1, 2) с использованием данных плотности, объемной массы, пористости, предела прочности на сжатие (вкрест слоистости) в воздущно-сухом и водонасыщенном состоянии, а также химического состава (сокращенный анализ) 170 проб. При построении графиков зависимостей между объемной массой и пределами прочности использованы данные по отдельным образцам (не менее пяти в каждой пробе).

Минеральная плотность отдельных разновидностей известняков колеблется от $2,71-2,78$ г/см ${ }^{3}$, в преобладающем большинстве составляет $2,72-2,74$ г/см³. Содержание же составляющих породу компонентов (таблица) имеет значительные колебания. К примеру - предельные содержания терригенного материала (нерастворимого остатка) составляют 0,60 и $17,9 \%$. Так как количественное содержание нерастворимого остатка на минеральной плотности пород четко не отражается, то его плотность должна быть близка плотности минералов кальцита $(2,6-$ $\left.2,8 \mathrm{r} / \mathrm{cm}^{3}\right) \cdot$ и доломита $\left(2,8-2,9 \mathrm{r} / \mathrm{cm}^{3}\right)$.

Объемная масса пород зависит от плотности минерального скелета и пористости. Поскольку минеральная плотность рассматриваемых разновидностей на изменение минерального состава, как отмечалось выше, практически не реагирует, то изменение объемной массы должно связываться с пористостью пород.

Как видно из графика (рис. $1, a$ ), между объемной массой и пористостью известняков имеется прямая зависимость. При этом четко выделяется, что большей пористостью и меньшей объемной массой отличаются известняки пяэскюлаской $\left(\mathrm{O}_{2} \mathrm{kh}^{\mathrm{ps}}\right)$ и куртнаской $\left(\mathrm{O}_{2} \mathrm{kh}{ }^{\mathrm{k}}\right)$ пачек, в которых больше терригенного компонента (таблица). Для подтверждения данного вывода был построен график зависимости пористости от содержания нерастворимого остатка (рис. 1,6$)$, на котором хорошо наблюдается закономерное увеличение пористости согласно увеличению содержания нерастворимого остатка.

С уменьшением размерности частиц и с увеличением их отсортированности пористость обычно возрастает (Дортман и др., 1984), но в исследуемом ряду известняков эта закономерность не наблюдается. Наименьшей пористостью отличаются мелко- до грубо-, в основном крупно- до среднекристаллические известняки, за ними, по увеличению пористости, следуют скрыто-, микро- и тонкокристаллические известняки. Увеличение пористости в связи с увеличением содержания терригенного материала, по всей вероятности, имеет генетическое обоснование. При диагенезе зернистого карбонатного осадка условия передвижения растворов благоприятные и основное количество первичных пустот и пор заполняется вторичным кальцитом. При увеличении же содержания нерастворимого остатка, который в объеме $70 \%$ представлен пелитовой фракцией и имеет практически мономинеральный гидрослюдистый состав (Пылма, 1982), миграция растворов в осадке при диагенезе из-за набухания глинистого составляющего затруднена и поровое пространство остается частично незаполненным. Составные компоненты пород в этом случае сцементированы в основном первичным осажденным кальцитовым и глинистым цементом.

Строение горной породы и характер связи между ее частицами является определяющим фактором прочностных свойств. Для исследования взаимосвязи между прочностью и строением пород характеристикой 


\begin{tabular}{|c|c|c|c|c|c|c|c|}
\hline \multirow{2}{*}{$\begin{array}{c}\text { Название } \\
\text { породы и } \\
\text { стратигра- } \\
\text { фический } \\
\text { индекс }\end{array}$} & \multirow{2}{*}{ 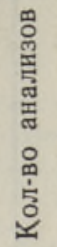 } & \multicolumn{2}{|c|}{$\begin{array}{c}\text { Содержание } \\
\mathrm{CaCO}_{3}, \%\end{array}$} & \multicolumn{2}{|c|}{$\begin{array}{c}\text { Содержание } \\
\mathrm{CaMg}\left(\mathrm{CO}_{3}\right)_{2}, \%\end{array}$} & \multicolumn{2}{|c|}{$\begin{array}{c}\text { Содержание } \\
\text { нерастворимого } \\
\text { остатка, \% }\end{array}$} \\
\hline & & $\frac{\text { предельн. }}{\text { среднее }}$ & $\begin{array}{l}\text { преоб- } \\
\text { ладаю- } \\
\text { щее * }\end{array}$ & $\frac{\text { предельн. }}{\text { среднее }}$ & $\begin{array}{l}\text { преоб- } \\
\text { ладаю- } \\
\text { щее }\end{array}$ & $\frac{\text { предельн. }}{\text { среднее }}$ & $\begin{array}{l}\text { преоб- } \\
\text { ладаю- } \\
\text { щее }\end{array}$ \\
\hline
\end{tabular}

\section{Средне- до}

крупнокри-

сталлический

цистондный

известняк

$\left(\mathrm{O}_{2} \mathrm{vs}\right)$

Скрытокри-

сталлический

бногермный

известняк

$\left(\mathrm{O}_{2} \mathrm{vs}\right)$

Микрокри-

сталлический

известняк с

мелким дет-

ритом

$\left(\mathrm{O}_{2} \mathrm{khps}\right)$

Тонкокристаллический известняк с

мелким детритом

$\left(\mathrm{O}_{2} \mathrm{khk}\right)$

$33 \quad \frac{87,61-}{97,75} \quad 92-97 \quad \frac{0,73-6,71}{4,25} \quad 2,5-5,5 \quad \frac{0,60-7,76}{1,96} \quad 0,8-2,5$

$8 \quad \frac{\begin{array}{l}79,01- \\ 94,12\end{array}}{89,74} \quad 89-92 \quad \frac{2,23-9,27}{5,48} \quad 3,5-6,5 \quad \frac{4,32-14,48}{5,98} \quad 4,0-5,0$

$42 \frac{\begin{array}{l}76,55-50 \\ 86,54\end{array} \quad 83-87}{\frac{92,32}{7,72}} \quad 5-11 \quad \frac{3,97-15,44}{7,84} \quad 6,0-9,0$

$48 \quad \frac{73,69-73}{78,91} \quad 76-81 \quad \frac{3,10-16,22}{10,0} \quad 4,5-10 \quad \frac{8,17-17,9}{14,33} \quad 13,0-16,0$

* Здесь и далее - более $70 \%$ встречаемости.

строения была выбрана объемная масса. Объемная масса, как доказано выше, хорошо коррелирует с пористостью и через нее - с составом пород. Кроме того, объемная масса каждого испытываемого на прочность образца породы определяется отдельно, что дает возможность сравнить показатели одного и того же образца и тем самым повысить достоверность получаемых результатов.

На рис. 2 вырисовывается определенная зависимость между объемной массой и пределом прочности известняков как в сухом, так и в водонасыщенном состоянии: чем выше объемная масса, тем выше предел прочности пород. Аналогичные данные были получены и В. И. Чельцовым (1961) по карбонатным породам Мелехово-Федотовского месторождения. Сравнение графиков отдельных литологических разновидностей показывает, что наибольшей прочностью как в сухом, так и в водонасыщенном состоянии отличаются тонкокристаллические известняки, за ними следуют микро-, скрыто- и среднекристаллические - т. е. практически повторяется ряд по увеличению пористости и содержания нерастворимого остатка. Однако увеличение предела прочности микро- и тонко-

Рис. 2 (рисунок см. на обороте). Зависимость предела прочности на сжатие от объемной массы. а) мелко- до крупнокристаллический известняк вазалеммаской свиты $\left(\mathrm{O}_{2} \mathrm{vs}\right)$, б) скрытокристаллический известняк вазалеммаской свиты $\left(\mathrm{O}_{2} \mathrm{vs}\right)$, в) микрокристаллический известняк пяэскюлаской пачки $\left(\mathrm{O}_{2} \mathrm{khps}\right)$, 2) тонкокристаллический известняк куртнаской пачки $\left(\mathrm{O}_{2} \mathrm{kh}\right) .1$ - предел прочности в воздушно-сухом состоянии, $2-$ то же, в водонасыщенном состоянин, 3 - линия преобладания значений предела прочности в воздущно-сухом состоянин, 4 - то же, в водонасыщенном состоянии. 



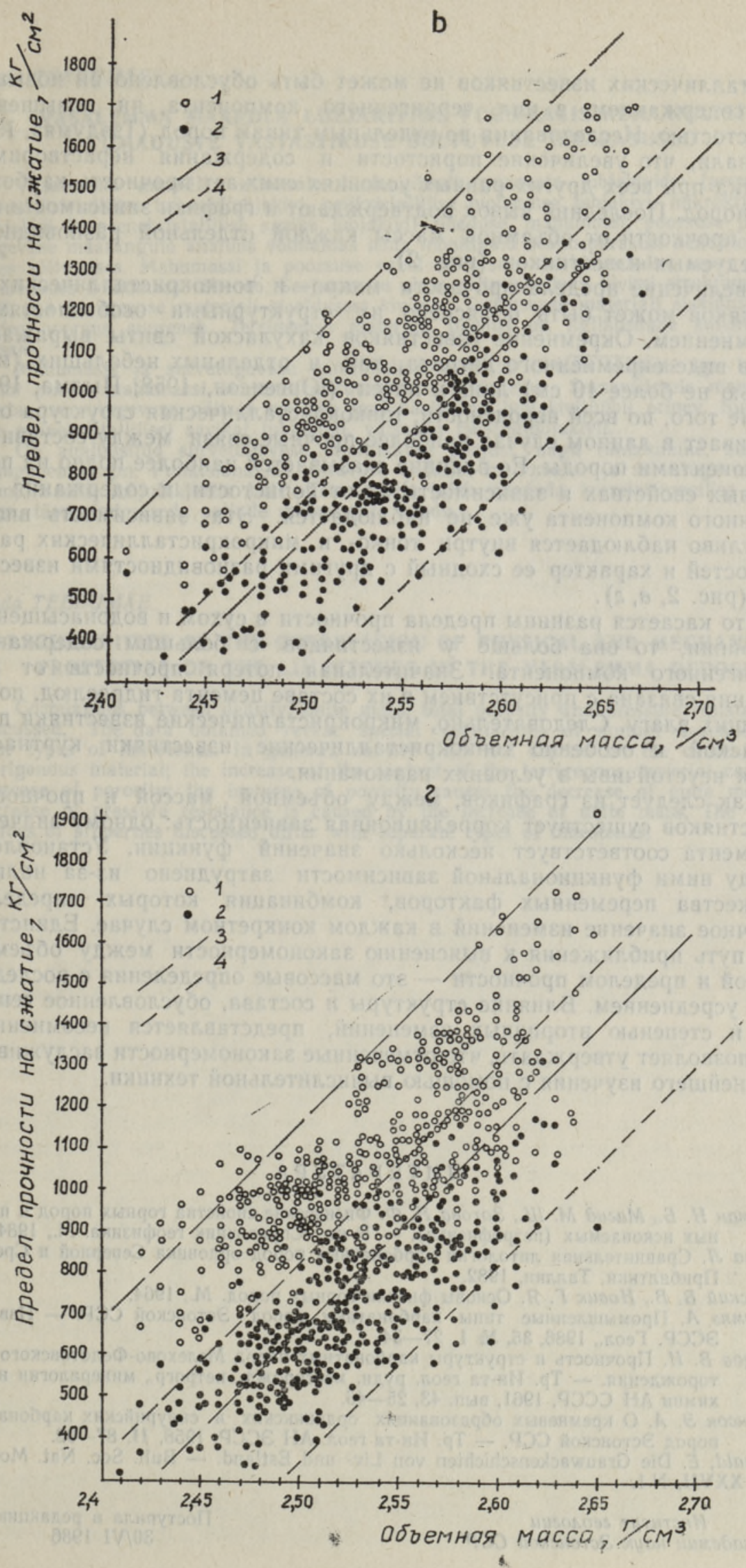
кристаллических известняков не может быть обусловлено ни повышенным содержанием в них терригенного компонента, ни повышенной пористостью. Исследования по отдельным типам пород (Тээдумяэ, 1986) показали, что увеличение пористости и содержания нерастворимого остатка при всех других равных условиях снижает прочность карбонатных пород. Последний вывод подтверждают и графики зависимости предела прочности от объемной массы каждой отдельной разновидности исследуемых известняков (рис. 2).

Увеличение предела прочности микро- и тонкокристаллических известняков может быть объяснено их структурными особенностями и окремнением. Окремнение известняков кахулаской свиты выражается как в виде окремненного детрита, так и отдельных небольших (мощностью не более 10 см) линз и пятен (Юргенсон, 1958; Пылма, 1982). Кроме того, по всей вероятности, тонкокристаллическая структура обусловливает в данном случае наиболее прочные связи между составными компонентами породы. Ее влияние сказывается наиболее полно на прочностных свойствах и зависимости их от пористости, и содержания терригенного компонента уже не наблюдается. Эта зависимость вполне отчетливо наблюдается внутри тонко- и микрокристаллических разновидностей и характер ее сходный с другими разновидностями известняков (рис. $2, в, 2)$.

Что касается разницы предела прочности в сухом и водонасыщенном состоянии, то она больше у известняков с бо́льшим содержанием терригенного компонента. Значительная потеря прочности от размокания связана с присутствием в их составе цемента гидрослюд, поглощающих влагу. Следовательно, микрокристаллические известняки пяэскюлаской и особенно тонкокристаллические известняки куртнаской пачек неустойчивы в условиях размокания.

Как следует из графиков, между объемной массой и прочностью известняков существует корреляционная зависимость: одному значению аргумента соответствует несколько значений функции. Установление между ними функциональной зависимости затруднено из-за наличия множества переменных факторов, комбинация которых определяет конечное значение изменений в каждом конкретном случае. Единственный путь приближения к выяснению закономерности между объемной массой и пределом прочности - это массовые определения с последующим усреднением. Влияние структуры и состава, обусловленное генезисом и степенью вторичных изменений, представляется несомненным. Это позволяет утверждать, что отмеченные закономерности заслуживают дальнейшего изучения с помощью вычислительной техники.

\section{ЛИТЕРАТ У Р А}

Дортман Н. Б., Магид М. Ш., Зотова Н. Ф. Физические свойства горных пород и полез-

Пылма Л. Сравннтельная литология карбонатных пород ордовика Северной и Средней
Прибалтики. Таллин, 1982. Прибалтики. Таллин, 1982.

Ржевский В. В., Новик $Г$. Я. Основы фнзнки горных пород. М., 1964.

Тээдумяэ А. Промышленные типы карбонатных пород Эстонской ССР. - Изв. АН ЭССР. Геол., 1986, 35, № $1,27-34$.

Чельцов В. Н. Прочность и структуры карбонатных пород Мелехово-Федотовского месторождения. - Тр. Ин-та геол. рудн. месторожд., петрогр., минералогин и геохнмии АН СССР, 1961, вып. 43, 25-46. Юргенсон Э. А. О кремневых образованиях ордовнкских и силурийских карбонатных
пород Эстонской ССР. - Тр. Ин-та геол. АН ЭССР, 1958, II, 87-92. Eichwald, E. Die Grauwackenschichten von Liv- und Estland. - Bull. Soc. Nat. Moscou,
1854, XXVII, N 1.

$\begin{array}{cc}\text { Институт геологии } & \text { Поступнла в редакцию } \\ \text { Академии наук Эстонской ССР } & 30 / \mathrm{VI} 1986\end{array}$




\section{VASALEMMA MAARDLA LUBJAKIVIDE FUUSIKALIS-MEHAANILISTE} OMADUSTE VASTASTIKUSE SOLTUVUSE ISEÅRASUSED

Vasalemma maardlas esinevate litoloogiliselt erinevate lubjakivide (peene- kuni jämedakristallilise tsüstoidlubjakivi, peitkristallilise biohermse lubjakivi, mikrokristallilise lubjakivi ja peenekristallilise savika lubjakivi) tiheduse, mahumassi, poorsuse ja survetugevuse määrangute analüüs võimaldas leida mõningaid seaduspärasusi nende omavahelises sōltuvuses. Mahumassi ja poorsuse vahel on otsene funktsionaalne seos: poorsuse suurenedes mahumass väheneb. Seejuures ei olene sõltuvuse laad kivimi struktuuritüübist, küll aga terrigeense materjali sisaldusest kivimis. Terrigeense materjali sisalduse suurenedes poorsus suureneb. Terrigeense materjali tihedus on ligilähedane kaltsiidi tihedusele.

Mahumassi ja survetugevuse omavaheline sõltuvus ilmneb selgèsti iga lubjakivitüübi puhul: mahumassi suurenedes suureneb survetugevus. Samaväärsele mahukaalule vastav survetugevuse näitaja on aga igal käsitletud lubjakivitüübil erinev. Suurim on see peenekristallilisel savikal lubjakivil, väikseim tsüstiidlubjakivil.

On analüüsitud survetugevuse muutlikkuse põhjusi, nagu ränistumine, struktuurikomponendid jm. Funktsionaalse sōltuvuse leidmist mahumassi ja survetugevuse vahel komplitseerib mõjufaktorite hulk. Tõenäoliselt tuleb piirduda korrelatsioonilise sõltuvusega, täpsustades seda paljude määrangute kaudu.

\section{Aada TEEDUMAE}

\section{PECULIARITIES OF THE CORRELATION OF PHYSICAL AND MECHANICAL PROPERTIES OF THE LIMESTONES IN THE VASALEMMA DEPOSIT}

Correlations between density, unite mass, total porosity and pressure resistance are discussed. The data obtained reveal special regularities of mutual dependence for four types of limestones. In general, density does not depend on the content of the terrigenous material; the increase of the content of the terrigenous material causes the increase of porosity; the increase of porosity causes the decrease of unite mass; the increase of pressure resistance is caused by the increase of unite mass. The concrete values of properties discussed differ with separate types of limestones. 